\section{Reply to Massimo Valerio, Mark Emberton, and Hashim U. Ahmed's Letter to the Editor re: Henk G. van der Poel, Roderick C.N. van den Bergh, Erik Briers, et al. Focal Therapy in Primary Localised Prostate Cancer: The European Association of Urology Position in 2018. Eur Urol 2018;74:84-91}

We thank the authors for their comments on our publication [1] and understand their need for a reply considering their excellent efforts in the field of focal therapy (FT). We appreciate the opportunity to provide a point-by-point reply to address each of their remarks in an orderly fashion.

1. The position papers are requested by the European Association of Urology (EAU) executive. The proposal was made to the EAU Guidelines Office panel that has studied the scientific literature on the topic at hand. The position manuscripts come into being in close collaboration with the EAU executives and are therefore labelled EAU Position Paper. It is far from a survey and neither a consensus nor a systematic review. It is meant to help the urological field progress in a scientific manner with wording that might diverge from the guidelines themselves if needed.

2. The randomised controlled trial on local therapy mentioned did not include FT. Therefore, using the equivalence of survival in these trials as a claim that FT will have similar survival outcomes is not valid, and possibly presumptuous.

3. There is no question on the benefits of FT with respect to functional outcomes when compared with whole-gland treatment. The relevant issue for FT is to demonstrate robust evidence of either equivalence or noninferiority in terms of oncological effectiveness for patients who do require radical treatment. The argument that FT has superior toxicity and functional outcomes to radical treatments becomes relatively meaningless in the absence of such evidence.

4. The support for active surveillance (AS) stems from the fact that overdiagnosis and, more importantly, overtreatment are major issues in the management of localised prostate cancer. AS is a means of addressing these issue. FT will not solve this, especially considering that the toxicity of FT still exceeds that of AS. If we accept the premise that patients who do not need treatment should not receive any treatment, but those that do should, then on the basis of the present evidence, it would be difficult to see where FT fits in current management pathways.

5. Partial nephrectomy is recommended on the assumption that preserving renal function may improve overall survival. Preserving prostate function certainly will not. Thus, this analogy is flawed. Moreover, the FT study quoted [2] is a prospective but uncontrolled single-arm case series, which hardly elevates the current evidence base.

6. In formulating our position, our paper was based on a robust review of the current evidence base. The Young Academic Urologists (YAU) survey cited was actually a survey of opinions and can be interpreted as aspirational, and not underpinned by any reliable data assessment. Nevertheless, our position actually aligns with the findings of the YAU survey, which is that FT is not regarded as the standard of care at present, but it should continue to be assessed and studied in carefully controlled prospective studies (ie, investigational trials).

7. The need for salvage prostatectomy after radiotherapy for local recurrence should be weighted in the treatment choice for these men. Moreover, considering the claim of the FT field that treatment can be easily repeated when needed and at least $20 \%$ (of often multifocal) cases will recur, this claim should be supported with sufficient clinical evidence.

Again we thank the authors for allowing us to reiterate our position and we certainly support any ongoing research in the field of FT.

Conflicts of interest: The authors have nothing to disclose.

\section{References}

[1] van der Poel HG, van den Bergh RCN, Briers E, et al. Focal therapy in primary localised prostate cancer: the European Association of Urology position in 2018. Eur Urol 2018;74:84-91. 
[2] Guillaumier S, Peters M, Arya M, et al. A multicentre study of 5-year outcomes following focal therapy in treating clinically significant nonmetastatic prostate cancer. Eur Urol. In press. https://doi.org/10. 1016/j.eururo.2018.06.006.

Henk G. van der Poel ${ }^{\mathrm{a}, *}$ Roderick C.N. van den Bergh ${ }^{\mathrm{a}}$ Erik Briers ${ }^{\mathrm{b}}$ Philip Cornford Alex Govorov ${ }^{\mathrm{d}}$ Ann M. Henry Thomas B. Lam ${ }^{\mathrm{f} g}$ Malcolm D. Mason ${ }^{\mathrm{h}}$ Olivier Rouvière ${ }^{\mathrm{i}}$ Maria De Santis ${ }^{\mathrm{j}, \mathrm{k}}$

Peter-Paul M. Willemse Hendrik van Poppel $^{\mathrm{m}}$ Nicolas Mottet ${ }^{n}$

a Department of Urology, Netherlands Cancer Institute, Amsterdam,

The Netherlands

${ }^{\mathrm{b}}$ Patients Advocate, Hasselt, Belgium ${ }^{\mathrm{c}}$ Royal Liverpool and Broadgreen Hospitals NHS Trust, Liverpool, UK
${ }^{\mathrm{d}}$ Department of Urology, Moscow State University of Medicine and Dentistry, Moscow, Russia

e Leeds Cancer Centre, St. James's University Hospital, Leeds, UK ${ }^{\mathrm{f}}$ Academic Urology Unit, University of Aberdeen, Aberdeen, UK ${ }^{\mathrm{g}}$ Department of Urology, Aberdeen Royal Infirmary, Aberdeen, UK ${ }^{\mathrm{h}}$ Division of Cancer $\mathcal{E}$ ' Genetics, School of Medicine Cardiff University, Velindre Cancer Centre, Cardiff, UK ${ }^{\mathrm{i}}$ Hospices Civils de Lyon, Radiology Department, Edouard Herriot Hospital, Lyon, France

${ }^{\mathrm{j}}$ Clinical Trials Unit, University of Warwick, Coventry, UK ${ }^{\mathrm{k}}$ Department of Urology, Medical University of Vienna, Vienna, Austria

${ }^{1}$ Department of Urology, University Utrecht, Utrecht, The Netherlands ${ }^{\mathrm{m}}$ Department of Urology, University Hospital K.U. Leuven, Leuven, Belgium ${ }^{\mathrm{n}}$ Department of Urology, University Hospital, St. Etienne, France

${ }^{*}$ Corresponding author. Department of Urology, The Netherlands Cancer Institute, Antoni-Van Leeuwenhoek Hospital, Plesmanlaan 121, Amsterdam 1066CX, The Netherlands. Tel.: +31-20-5122553; Fax: +3120-5122554.

E-mail addresses: h.vd.poel@nki.nl (H.G. van der Poel). h_vanderpoel@hotmail.com (H.G. van der Poelh.vd.poel@nki.nl).

August 30, 2018 